\title{
Terrorism and the Stock Market: A Case Study for Turkey Using STR Models
}

\author{
Ayşegül Çorakçi Eruygur* and Tolga Omay
}

\author{
Cankaya University Eskişehir Yolu, 29. Km, Turkey
}

\begin{abstract}
Several attempts have been made in the literature to analyze the detrimental effects of terrorist activities on the stock market. However, in neither of these studies the effects of terrorist activities on stock returns are investigated through employing nonlinear models in spite of the fact that most financial data is shown to exhibit nonlinear behaviour. This study, therefore, aims to contribute to this growing area of research by exploring the potential nonlinear effects of terrorist activities on stock returns by employing smooth transition regression (STR) models. Our results show that terrorism has a statistically significant negative effect on the stock index when the intensity of terrorist activities passes a certain threshold level. This negative effect continues for terrorist activities below this threshold level, but becomes statistically insignificant. This study by conducting the analysis within a nonlinear framework offers important insights into the investors who want to make portfolio diversification strategies against terrorism risk.
\end{abstract}

Keywords: Stock market, Terrorist activity, STR nonlinearity.

\section{INTRODUCTION}

The increased number of terrorist events witnessed in the last decade such as the 9/11, Madrid 2004 and London 2005 terrorist attacks have demonstrated us that terrorism can be a crucial risk factor for investors in the stock markets. Until these events, terrorism had not received much attention from financial researchers. However, these terrorist attacks had especially a detrimental effect on the financial markets and after these widespread negative effects were observed, a growing interest from financial researchers has been dedicated to the effects of terrorist activities on the stock markets.

The studies which investigate the effects of terrorist activities on stock markets include Chen and Siems (2004), Eldor and Melnick (2004), Karolyi and Martell (2005), Johnston and Nedelescu (2005), Arin et al. (2008) and Chesney et al. (2011). The negative effects of terrorism on investor behavior are described extensively in by Karolyi (2006). Karolyi (2006) has argued that negative future expectations of investors are directly reflected in stock prices, since an investor once informed about some terrorist attack easily escapes this market and substitutes her investments in this insecure market with other more established and secure financial assets. Chen and Siems (2004) have studied the effects of terrorist attacks on global capital markets by employing an event study methodology and found out that the U.S. capital markets converge to

\footnotetext{
*Address correspondence to this author at the Cankaya University Eskişehir Yolu, 29. Km, Turkey; Tel: (90) 312 2331267;

E-mail: aeruygur@cankaya.edu.tr, aysegul.eruygur@gmail.com

JEL Codes: C22, G1.
}

stability faster than the other global capital markets. Eldor and Melnick (2004) have illustrated that financial markets are capable in pricing the shocks connected with terrorist attacks by using time-series analysis. Johnston and Nedelescu (2005) have investigated the same issue by using main incidents taking place worldwide and they claimed that authorities and coordinated efforts among them prevent financial markets and financial markets to be efficient in absorbing the shocks caused by terrorist attacks. Karolyi and Martell (2005) have examined the stock price shock of terrorist attacks and demonstrated that the damages by these attacks are more influential in more richer or democratic countries. Arın et al. (2008) have also investigated the effects of terrorism on the financial markets. They have found that terrorism has a significant impact on both stock markets and the stock market volatility, and the magnitudes of these effects are larger in emerging markets. Finally, Chesney et al. (2011) investigated empirically the impact of terrorism on the behavior of stock, bond and commodity markets. They have considered terrorist events that took place in 25 countries over an 11-year time period and implemented an event-study approach, a nonparametric methodology, and a filtered GARCH-EVT approach. By using these methodologies they have documented the detrimental effects of terrorist attacks and as a result they have instructed investors how to make portfolio diversification strategies against terrorism risk.

In the previous studies the detrimental effects of terrorist activities on the stock market are assessed by considering the effects of these attacks on the mean (first moment) and the variance (second moment) of the stock returns with three different ways: event 
studies, univariate time series analysis and multivariate time series techniques that consider $\mathrm{GARCH}$ effects ${ }^{1}$. However, one major drawback of all these studies is that they overlook the fact that the mean equation of the stock returns can be characterized by strong nonlinearities. Many economists currently recognize that many financial variables follow nonlinear processes (see, for example, Granger and Teräsvirta, 1993; Campbell et al., 1997;McMillan, 2003; Omay and Hasanov, 2008). If a variable is nonlinear, this may be caused by its conditional mean or variance. However, the research to date has tended to focus on nonlinearity arising from conditional variance of the stock returns rather than their mean and thereby utilized the ARCH or GARCH models of Engel (1982) and Bollerslev (1986). Therefore, one important question that still needs to be answered is whether the results of these studies change when the possible nonlinearity in the conditional mean of the stock returns are to be taken into account. Along these lines, Ludenbergh and Teräsvirta (1998) have proposed the smooth-transition autoregressive (STAR) -STGARCH model that permits for nonlinearity in both conditional mean and variance of the series in question and employed this model to investigate the Swedish OMX index. In addition, Chan and McAleer (2002, 2003) have studied statistical features and empirical subjects considering estimation of STAR-STGARCH models with empirical analysis of S\&P 500, Nikkei 225 and Hang Seng Indices. For the Turkish stock market Hasanov and Omay (2008) have examined the nonlinear predictability of the stock returns using the STAR model and documented that the Turkish stock market is characterized by strong nonlinearities. This finding has motivated us to construct a nonlinear model to analyze the effects of terrorism on the Turkish stock market.

Stock market returns may display nonlinear behavior due to existence of transaction costs and market frictions. In the presence of bid-ask spread, short selling, borrowing constraints, and other transaction costs; arbitrage loses its profitability when the deviations of stock returns from their equilibrium values are small (Hasanov and Omay, 2008) ${ }^{2}$. Therefore, the stock returns will converge to their equilibrium value only for large enough deviations from

\footnotetext{
${ }^{1}$ The findings of these studies are well summarized in Arin et al. (2008) and Chesney el al. (2011). Therefore, for a more detailed literature survey one can refer to these papers.

${ }^{2}$ For more details see Hasanov and Omay (2008)
}

the equilibrium return ( $\mathrm{He}$ and Modest, 1995). Along this lines, we have used the STR model proposed by Teräsvirta and Anderson (1992) to analyze the effects of terrorist attacks on the Turkish stock market ${ }^{3}$.

The remaining of the paper is organized as follows. In section 2 the econometric model is presented along with the estimates of the linear and STR models. Section 3 concludes.

\section{THE ECONOMETRIC MODEL, DATA AND EMPIRICAL RESULTS}

A smooth transition (STR) model for a univariate time series $y_{t}$ is given by:

$y_{t}=\lambda_{1,0}+\lambda_{1}^{\prime} x_{t}+\left(\lambda_{2,0}+\lambda_{2}^{\prime} x_{t}\right) \cdot G()+.u_{t}$

where $x_{t}$ is a vector of variables, $u_{t}$ is a normally distributed error term with zero mean that is homoscedastic over states. The transition function $G\left(s_{t} ; \gamma, c\right)$ is a continuous function bounded between $[1,0]$. Consequently, the smooth transition model can be seen as a nonlinear model that allows two states, which can be identified with the extreme values of the transition function, $G\left(s_{t} ; \gamma, c\right)=0$ and $G\left(s_{t} ; \gamma, c\right)=1$, where the transition from one regime to the other is slow and regular. The parameter $\gamma$ identifies the smoothness of the transition, and thus, gives the slope function of the transition function. The two states are connected with small and large values of the transition (state) variable $s_{t}$ relative to the threshold parameter $c$.

The transition function $G\left(s_{t} ; \gamma, c\right)$ can take two forms: The logistic transition function and the exponential function. These are given in equations (2.2) and (2.3), respectively, where $\sigma_{s_{t}}$ denotes the sample standard deviation of the state variable $s_{t}$. The STR models with functions given in equations (2.2) and (2.3) are named as the logistic STR (LSTR) and exponential STR (ESTR) models, respectively.

$$
\begin{aligned}
& G(.)=\frac{1}{1+\exp \left(-\gamma\left(s_{t}-c\right) / \sigma_{s_{t}}\right)} \\
& G(.)=1-\exp \left(-\gamma\left(s_{t}-c\right)^{2} / \sigma_{s_{t}}^{2}\right)
\end{aligned}
$$

While the LSTR model is suitable for modeling states that have different dynamics, the ESTR model is

\footnotetext{
${ }^{3}$ For a further discussion on STR models see Omay et al. (2013).
} 
useful for cases in which the states display symmetric behavior. The logistic function given in equation (2.2) is suitable for modeling various structures depending on whether the returns obtain large or small values. The LSTR model may be used to model distinct investor behavior in progressing and regressive markets. In addition, the LSTR model may be utilized also in cases where different market frictions lead to different effects depending on whether the stock prices are rising or falling. Thus, the LSTR model can be used to explain the circumstances where slumps or booms have quite different nonlinear dynamics. However, in an ESTR model the transition arises symmetrically for $s_{t}$ about the threshold parameter $c$ and thereby, will indicate similar dynamics for periods of slump and booms (see Teräsvirta and Anderson, 1992).

The identification of STR models is obtained in six steps (Van Dijk, 1999): First, a suitable linear autoregressive model for the stock return series is identified. Second, the linearity test is applied. In other words, one should test whether the stock returns follow a linear process (null hypothesis) or STAR-type of nonlinearity (alternative hypothesis). If the stock returns are found to follow a linear process, then choose the suitable state variable $s_{t}$ and the structure of the state function $G($.$) . In the third step, estimate the$ parameters of the selected model and use diagnostic tests to evaluate its sufficiency. The existing model should be modified if it does not pass the diagnostic checks. In the last step, the model could be used for descriptive purposes if it passes all the misspecification tests ${ }^{4}$.

After selecting the state variable and the form of the transition function, the STAR models can be estimated by using nonlinear optimization procedures. The main problem involved with nonlinear optimization is being able to choose good starting values, hence, a suitable way to get reasonable starting values for the nonlinear optimization algorithm is to carry out a two-dimensional grid search over $\gamma$ and $c$, and choose those parameter estimates that minimize sum of square residuals of variance of the residual term. After estimation, we carried out misspecification tests to assess the estimated STAR model. Mainly, we carried out diagnostic tests for skewness and kurtosis, autoregressive conditional heteroskedasticity $(\mathrm{ARCH})$ test of Engle (1982), and the LM tests for autocorrelation, parameter constancy, and additive nonlinearity, as suggested by Eitrheim and Terasvirta (1996). If the estimated model passes all these

\footnotetext{
${ }^{4}$ For other details involved in the estimation and evaluation phases, the researchers can read Teräsvirta and Anderson (1992), Hasanov and Omay (2008) and Omay et al. (2013)
}

diagnostic tests, then it can be employed for descriptive and/or forecasting purposes as we mentioned above.

In this paper we consider monthly returns of the Istanbul Stock Exchange (ISE) index and the terror index that is constructed and used in Araz et al (2009), covering the period 1987:12-2003:12. The index data is taken from electronic data distribution system of the Central Bank of Republic of Turkey. We compute the monthly returns as $y_{t}=\log X_{t}-\log X_{t-1}$ where $X_{t}$ is ISE100 index.

To carry out the empirical specification methodology outlined above, we first estimate a linear autoregressive model for the monthly returns. The model is obtained by deleting the statistically insignificant lags. Initially, we have specified the maximum lag order as 12, with intermediate lags deleted one after another as they are found statistically insignificant ${ }^{5}$ given that such deletions decrease the AIC. The best fitting linear model for returns is given by:

$$
\begin{aligned}
& y_{t}=\underset{(0.013)}{0.033}+\underset{(0.077)}{0.312} y_{t-1}-\underset{(0.080)}{0.163} y_{t-2}+\underset{(0.081)}{0.132} y_{t-3}+\varepsilon \\
& \hat{\sigma}_{\varepsilon}^{2}=0.135, \mathrm{Sk}=0.002(0.987), \mathrm{Ku}=0.002(0.846) \\
& \mathrm{AIC}=1.305 \bar{R}^{2}=0.147, \mathrm{SEE}=0.138, \mathrm{RSS}=3.591, \\
& \mathrm{Q}(36)=30.829(0.713), \mathrm{ARCH}(1)=2.465(0.116), \\
& \mathrm{ARCH}(4)=4.808(0.307), J . B .=0.039(0.980),
\end{aligned}
$$

$\mathrm{LM}=12.204(0.142)$

where the heteroscedasticity consistent standard errors are given in paranthesis. The diagnostic test results for the linear model are given below equation (2.4). Here $\hat{\sigma}_{\varepsilon}^{2}$ denotes the residual variance, $\mathrm{Sk}$ is the skewness and $\mathrm{Ku}$ is the kurtosis of the distribution, $\mathrm{ARCH}(1)$ and ARCH (4) gives Engle's (1982) test for conditional heteroscedasticity for the lags 1 and 4, respectively, $\mathrm{Q}(36)$ reports the Ljung and Box (1978) Q statistic for 36 lags, JB is Jarque-Bera normality test, LM denotes Breush-Godfrey serial correlation Lagrange Multiplier test, SEE is standard error of estimate, AIC is the Akaike information criterion, BIC is the Bayesian information criterion, and RSS is sum of squared residuals. The values in parentheses next to the diagnostic statistics are their respective $p$-values. The estimated model given in equation (2.4) passes from all the diagnostic checks. Moreover, the $\mathrm{ARCH}$ test suggests no nonlinearity in the conditional variance.

After obtaining an adequate linear specification for the monthly returns, we add the terror variable

\footnotetext{
${ }^{5}$ The lags are deleted starting with the least statistically significant lag according to the $t$-ratio.
} 
Table 1: Linearity Tests and Transition Function Selection

\begin{tabular}{|c|c|c|c|}
\hline \multicolumn{4}{|c|}{ Panel A: Linearity Tests } \\
\hline \multirow[b]{2}{*}{ Candidate Transition Variables } & \multicolumn{3}{|c|}{ LM3 Statistic } \\
\hline & ISE Return & Terror & $\mathbf{T}$ \\
\hline Lag 1 & $1.730(0.064)$ & $1.568(0.104)$ & \\
\hline Lag 2 & $1.510(0.124)$ & $1.916(0.035)$ & \\
\hline Lag 3 & $1.657(0.080)$ & $1.000(0.450)$ & \\
\hline Lag 4 & $1.191(0.292)$ & $0.975(0.473)$ & \\
\hline Lag 5 & $2.156(0.015)$ & $2.046(0.023)$ & \\
\hline Lag 6 & $0.856(0.592)$ & $3.495(0.000)$ & \\
\hline $\operatorname{Lag} 7$ & $1.531(0.117)$ & $1.430(0.156)$ & $0.417(0.955)$ \\
\hline Lag 8 & $0.874(0.574)$ & $2.126(0.017)$ & \\
\hline $\operatorname{Lag} 9$ & $1.058(0.398)$ & $1.661(0.079)$ & \\
\hline Lag 10 & $1.539(0.114)$ & $1.449(0.148)$ & \\
\hline Lag 11 & $2.172(0.015)$ & $1.473(0.138)$ & \\
\hline Lag 12 & $2.289(0.010)$ & $1.317(0.213)$ & \\
\hline \multicolumn{4}{|l|}{ Panel B: Model selection tests } \\
\hline & \multicolumn{3}{|c|}{$\underline{\text { Test Statistics }}$} \\
\hline Selected transition variable & $\underline{\text { F1 }}$ & $\underline{\mathbf{F 2}}$ & $\underline{\text { F3 }}$ \\
\hline$t e r_{t-6}$ & $0.584(0.712)$ & $2.916(0.014)$ & $3.715(0.003)$ \\
\hline
\end{tabular}

Note 1: F-versions of the LM-type tests were used. $p$-values of the test statistics are reported.

Note 2: Linearity test can be also called as tests against STAR-type nonlinearity.

(denoted by ter) into equation (2.4) to detect the effect of terrorist activities on the stock returns in Turkey ${ }^{6}$.

$y_{t}=\underset{(0.072)}{0.316} y_{t-1}-\underset{(0.074)}{0.176} y_{t-2}+\underset{(0.072)}{0.182} y_{t-2}-\underset{(0.002)}{0.007} t e r_{t-1}+\varepsilon_{t}$

$\hat{\sigma}_{\varepsilon}^{2}=0.135, \mathrm{AIC}=1.305, \mathrm{Sk}=0.002(0.987)$,

$\mathrm{Ku}=0.002(0.846) \quad \bar{R}^{2}=0.173, \mathrm{SEE}=0.136, \mathrm{RSS}=3.480$

$\mathrm{Q}(36)=44.459(0.157), \mathrm{ARCH}(1)=4.438(0.035), \mathrm{ARCH}(4)=$

$7.036(0.133), J . B .=0.039(0.980), \mathrm{LM}=10.716(0.218)$

The diagnostic test results for the linear model are again given below equation (2.5) and the model given in equation (2.5) also passes from all diagnostic tests. The linear model estimates imply that our terror variable (ter) affects the monthly stock returns $(y)$ significantly negative. Therefore, as a second step, we continue with the linearity tests to confirm for

${ }^{6}$ We do apply the Granger causality test that the stock returns granger causes the terrorist activity. As expected there is no causality running from stock returns to terrorist activities. Therefore, we used the above linear ARDL model and proceeded with it also in the nonlinear modeling phase. nonlinearities in the conditional mean of the series under consideration ${ }^{7}$.

Panel A of Table 1 presents the results of the linearity tests. The null of linearity is rejected for different state variables considered. Nevertheless, the $p$-values of all LM-type statistics are smallest for $\mathrm{Ter}_{t-6}$ and hence, this variable was considered as the transition variable. Therefore, we focus on this variable hereafter.

Having chosen the most suitable state variable we carry out an order of $F$ tests as explained in Teräsvirta and Anderson (1992) to decide the structure of the transition (state) function. The $F$ statistics and corresponding $p$-values are documented in Panel B of Table 1. Since the F3 statistic has the smallest $p$-value, we choose the logistic function and estimate a LSTR

${ }^{7}$ It should be noted here that the studies that apply GARCH family models typically use high frequency data. Therefore, it was an expected result to find no nonlinearity in the conditional variance for our time series. Since we use monthly data, models with nonlinearity in conditional mean are more appropriate. 
model. Selection of the LSTR model has very significant implications concerning the dynamics of the stock market in Turkey. As mentioned above it implies that the adjustment paths to equilibrium witnessed in slumps and booms in the Turkish stock market are asymmetric.

The LSTAR model is estimated using nonlinear least squares, which is equivalent to quasi-maximum likelihood based on a normal distribution. Under certain (weak) regularity conditions, which are discussed in White and Domowitz (1984) and Pötscher and Prucha (1997), the NLS estimates are consistent and asymptotically normal. In order to obtain initial values to make possible the nonlinear optimization algorithm, we performed an extensive two-dimensional grid search over the parameters $\gamma$ and $c$, ranging $\gamma$ (after scaling) from 1 to 100 by 0.01 increments and ranging $c$ from -0.4 to 0.5 by 0.01 increments. Like in the case of the linear model, the intermediate lags were deleted before carrying out the estimation using the grid search optimal values of the $\gamma$ and $c$. The estimated LSTR model and the corresponding transition function are given in equations (2.6) and (2.7), respectively,

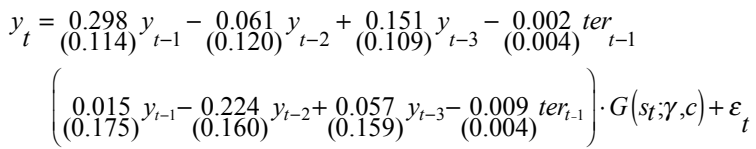

$G()=.\left(1+\exp \left\{-20.207\left(\text { ter }{ }_{t-6}-3.659\right)\right\}\right)^{-1}$

$\widehat{\sigma}_{\varepsilon}^{2}=0.133, \mathrm{AIC}=1.205, \bar{R}^{2}=0.195, \mathrm{SEE}=0.137, \mathrm{RSS}=3.342$,

$\mathrm{Q}(36)=46.086(0.121), \quad J . B .=0.160(0.922) \mathrm{LM}=12.204(0.142)$,

$\mathrm{F}_{\mathrm{AC}(1)}=2.785(0.097), \mathrm{F}_{\mathrm{PC}}=0.785(0.665)$ where the heteroscedasticity consistent standard errors are given in parentheses The diagnostic test results for the LSTR model are given below equation (2.7). Here $F_{A C(1)}$ and $F_{P C}$ denote the Eitrheim and Teräsvirta's (1996) test against first order serial correlation of residuals and parameter constancy, respectively. The values in parentheses next to the diagnostic statistics are their respective $p$-values. Diagnostic checks indicate that the estimated LSTR model is appropriate. Furthermore, as proposed by Eitrheim and Terasvirta (1996) we have tested the estimated LSTR model against additive nonlinearity, parameter constancy and remaining nonlinearity. The results of these tests are presented in Table 2. As it can be deduced from this table the LM test statistic provides no support for multiple regime and time varying STR models, which suggests that the fitted model contains no additional nonlinearity. The LM tests for parameter constancy and remaining autocorrelation allow the same conclusion. Hence, the estimated LSTR model is satisfactory. Consequently, the predicted LSTR models can be used to describe the relationship between the stock returns and terrorist activity in Turkey.

The transition parameter $(\gamma)$ is estimated significantly with a value that equals 20.207 . This suggests that there is a moderate speed of transition between the two regimes. This finding not only corroborates the existing stylized facts but underlines the fact that abrupt changes, as suggested by Markov and TAR models, are of little use in estimating the relation between terror and stock market returns in Turkey. For high values of $\gamma$, the stock returns may quite rapidly decrease (increase) if they are initially over (under) the band near the threshold value, $c$.

Valuable information to understand the model and the characteristics of the transition process are

Table 2: Test Against Additive Multiple Regime STR Model

\begin{tabular}{|c|c|c|c|}
\hline & \multicolumn{2}{|c|}{ LM3 Statistic } & Ter \\
\hline Candidate Transition Variables & ISE & 1.568 & 0.901 \\
\hline \hline $\operatorname{Lag} 1$ & 1.530 & 1.916 & 0.327 \\
\hline $\operatorname{Lag} 2$ & 1.510 & 1.000 & 0.741 \\
\hline $\operatorname{Lag} 3$ & 1.557 & 0.975 & 0.473 \\
\hline $\operatorname{Lag} 4$ & 1.191 & 1.046 & 0.023 \\
\hline $\operatorname{Lag} 5$ & 1.156 & 1.495 & 0.000 \\
\hline $\operatorname{Lag} 6$ & 0.856 & 1.430 & 0.156 \\
\hline $\operatorname{Lag} 7$ & 1.531 & 1.126 & 0.017 \\
\hline $\operatorname{Lag} 8$ & 0.874 & 1.661 & 0.079 \\
\hline $\operatorname{Lag} 9$ & 1.058 & 1.449 & 0.148 \\
\hline $\operatorname{Lag} 10$ & 1.539 & 1.473 & 0.138 \\
\hline $\operatorname{Lag} 11$ & 1.172 & 1.317 & 0.213 \\
\hline
\end{tabular}

Notes: F-versions of the LM-type tests were used. The table exhibits that none of the test are significant. 


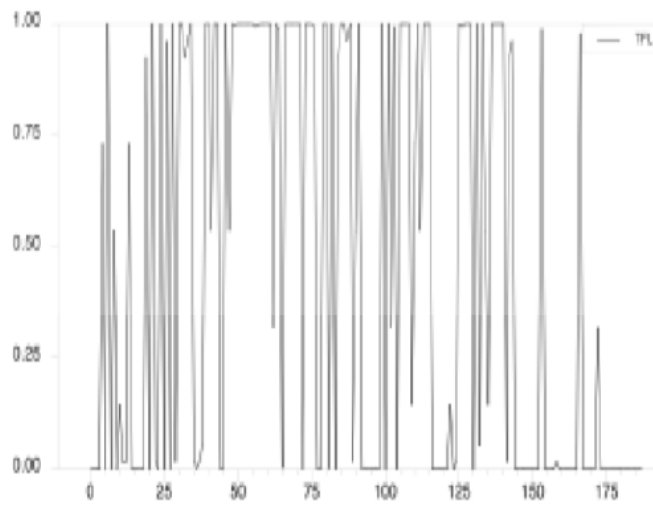

(a) Transition function against time

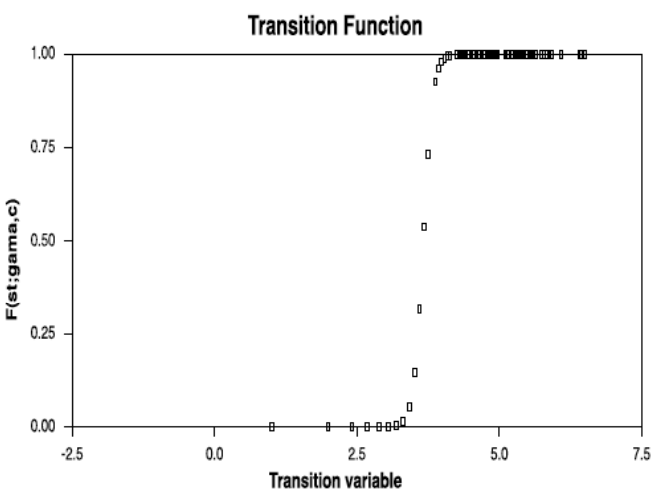

(b) Transition function against the transition variable

Figure 1: Transitions function in the LSTR model against time and transition variable.

conferred from the estimated values of the threshold and transition parameters, and the graph of the estimated transition function. Figure $\mathbf{1 b}$ shows the transition function. Obviously, there is a moderate change from one regime to the other. The estimated threshold value of $c=3.659$ points to the halfway point of the transition. ${ }^{8}$ This means that when the state variable $s_{t}=t e r_{t-6}$ equals the threshold value $c$, then $G\left(s_{t} ; \gamma, c\right)=1 / 2$. It indicates the half-way point between the low regime of terrorist activity and the high regime of terrorist activity in Turkey. There are many observations lying on both sides of this value, which underlines the existence and relevance of the two distinct regimes. These regimes can be defined according to whether the past values of $t e r_{t-6}$ are lower or larger than the estimated threshold value of $c=$ 3.659 .

In the low-terrorism state, when $\operatorname{ter}_{t-6}<3.659$ and $G\left(s_{t} ; \gamma, c\right)=0 \quad$ equation becomes $y_{t}=0.313 y_{t-1}-0.285 y_{t-2}+0.208 y_{t-3}-0.011$ ter $_{t-1}$. The coefficient capturing the effect of terror on stock returns has a value of -0.002 , but is statistically insignificant. In the high-terrorism state, when $\operatorname{ter}_{t-6}>3.659$ and $G\left(s_{t} ; \gamma, c\right)=1, \quad$ equation

becomes $y_{t}=0.298 y_{t-1}-0.061 y_{t-2}+0.151 y_{t-3}-0.009$ ter $_{t-1}$. In this high terrorist activity state the coefficient of the terror

\footnotetext{
${ }^{8}$ Since we are using a terrorism index, there is no direct interpretation of this threshold value. However, using the formula of the terrorism index, one could calculate that at this threshold value the sum of human fatalities, the number of people injured and the number of terrorist attacks equals 16.013. For example, if in a month a total of 3 terrorist attacks take place, resulting in 10 people to die and 5 people to become injured, then these numbers add up to18. Since this number is greater than 16 , we would then pass on to the higher-terrorism state.
}

variable amounts to -0.009 which is significant at the $10 \%$ significance level. Therefore, in this state an increase in terrorist activity is associated with severe declines in the stock returns in Turkey.

These results show that the lag of the terror index has a significantly negative impact on stock return in only the high terrorism state. Moreover, since we find different parameter estimates for the two regimes, the LSTR model implies asymmetric responses of stock returns to terrorist activities in Turkey. The nonlinear estimation results reveal that the detrimental effects of terror on stock returns are significant in magnitude during high-level terrorist activity periods than during low level terrorist activity periods. This result is quite intuitive and implies that the fear-of- heavy financial loss, experienced during the high-terrorism state, causes more distortions compared to the low-level terrorist activity regime.

\section{CONCLUSION}

The results presented in this paper provide strong evidence in favor of a non-linear relationship between terrorism and stock market returns. We demonstrate that the estimated STR model offers a better fit than a linear model representation. We show that while terrorist activity causes decreases in stock market returns during high level terrorist activity periods in Turkey, it has an insignificant negative effect in low regime periods. Thus, an increase in terrorist activity is not always associated with a decrease in stock returns. However, such shocks seem to have a negative impact on stock returns during periods of high-terrorist activity. As stated by Karolyi (2006) "unforeseen disastrous events emerges, investors can be induced to flee the market searching other and more stable financial instruments". Therefore, the threshold levels obtained 
from the nonlinear regression model presented here also gives important signals to financial investors. Financial investors who are less informed can use threshold levels as indicators of whether the market in question is risky or not. Whenever the terrorism index increases and passes the threshold level 3.659, the financial investor should decrease or stop his or her investment to the Istanbul Stock Exchange market, since this indicates that a regime change is occurring. Thus, by employing nonlinear models we have the opportunity to give a road map to investors who want to make portfolio diversification strategies against terrorism risk.

Our findings also have important implications for political decisions that may result in a regime switch, insofar as the magnitude of such shocks depends on whether terrorist activities are already running high or low. If the expected costs combined with terrorist movement do not exceed the expected costs associated with making recognitions, in the example we studied in this paper, below the threshold level of 3.659 , policy makers will have low incentive to stop terrorist activities because of the low costs associated with terrorism. On the other hand, if terrorist activities increase and pass the threshold level, the government should negotiate or allocate sufficient resources to nullify the threat. Therefore, the threshold level that is estimated using the STR model employed in this study is a good indicator for policy makers to react to occurring events. On the other hand, another important point is the structure of the stock markets. The Turkish stock exchange market (IMKB) has 425 companies as reported in 2014. Most of these 425 companies are small scale and financially weak companies which are intended to find fund in order to grow rapidly. Therefore, these types of companies are more fragile to a possible terrorist attack and the speculations that take place as a result. Hence, the government must put more restrictions on to the companies which are candidates for entering to the stock exchange market. Financially strong companies are less affected than these companies in such situations. Moreover, financial fragility of these small scale companies must be monitored carefully throughout the financial year and if they do not comply with the stock exchange market financial criteria, the stock market authorities should cancel their transaction in the market in order to form a more strong financial market.

\section{REFERENCES}

Araz-Takay, Bahar, Peren K. Arin, and Tolga Omay. 2009. "The Endogenous and Non-linear Relationship between Terrorism and Economic Performance: Turkish Evidence." Defence and Peace Economics 20(1):1-10.

http://dx.doi.org/10.1080/10242690701775509

Arin, K. Peren, Davide Ciferri, and Nicola Spagnolo. 2008. "The price of terror: The effects of terrorism on stock market returns and volatility." Economics Letters 101(3):164- 167. http://dx.doi.org/10.1016/j.econlet.2008.07.007

Bollerslev, Tim 1986. "Generalized Autoregressive Conditional Heteroskedasticity." Journal of Econometrics 31:307-327. http://dx.doi.org/10.1016/0304-4076(86)90063-1

Campbell, John Y, Andrew W. Lo, and Craig MacKinlay. 1997. The Econometrics of Financial Markets. Princeton: Princeton University Press.

Chan, Felix and Michael McAleer. 2002. "Maximum Likelihood Estimation of STAR and STAR-GARCH Models: Theory and Monte Carlo Evidence." Journal of Applied Econometrics 17(5):509-534. http://dx.doi.org/10.1002/jae.686

Chan, Felix and Michael McAleer. 2003. "Estimating Smooth Transition Autoregressive Models with GARCH Errors in the Presence of Extreme Observations and Outliers." Applied Financial Economics 13(8):581-592. http://dx.doi.org/10.1080/0960310022000029295

Chen, Andrew H. and Thomas F. Siems. 2004. "The Effects of Terrorism on Global Capital Markets." European Journal of Political Economy 20(2):349-366. http://dx.doi.org/10.1016/j.ejpoleco.2003.12.005

Chesney, Marc, Ganna Reshetar and Mustafa Karaman. 2011. "The Impact of Terrorism on Financial Markets: An Empirical Study." Journal of Banking and Finance 35(2):253-267. http://dx.doi.org/10.1016/j.jbankfin.2010.07.026

Eitrheim, Øyvind and Timo Teräsvirta. 1996. "Testing the Adequacy of Smooth Transition Autoregressive Models." Journal of Econometrics 74(1):59-75. http://dx.doi.org/10.1016/0304-4076(95)01751-8

Eldor, Rafi and Rafi Melnick. 2004. "Financial Markets and Terrorism." European Journal of Political Economy 20(2):367-386.

http://dx.doi.org/10.1016/j.ejpoleco.2004.03.002

Engle, Robert F. 1982. "Autoregressive Conditional Heteroscedasticity with Estimates of the Variance of United Kingdom Inflation." Econometrica 50(4):987-1007. http://dx.doi.org/10.2307/1912773

Ljung, Greta M. and George E. P. Box. 1978. "On a Measure of Lack of Fit in Time Series Models." Biometrika 65:297-303. http://dx.doi.org/10.1093/biomet/65.2.297

Hasanov, Mübariz and Tolga Omay. 2008. "Nonlinearities in Emerging Stock Markets: Evidence From Europe's Two Largest Emerging Markets." Applied Economics 40(20):26452658. http://dx.doi.org/10.1080/00036840600970310

He, Hua and David M. Modest. 1995. "Market Frictions and Consumption-Based Asset Pricing." Journal of Political Economy 103(1):94-117. http://dx.doi.org/10.1086/261977

Granger, Clive W.J. and Timo Teräsvirta. 1993. Modelling Nonlinear Economic Relationships. Advanced Texts in Econometrics. Oxford University Press.

Johnston, R. Barry and Oana M. Nedelescu. 2005."The Impact of Terrorism on Financial Markets." IMF Working Paper: WP $/ 05 / 60$.

Karolyi, G. Andrew. 2006. "Shock Markets: What Do We Know About Terrorism and the Financial Markets? Canadian Investment Review.

Karolyi, G. Andrew and Martell, R., 2005. "Terrorism and the Stock Market." Ohio State University WP.

Lundbergh, Stefan and Timo Teräsvirta. 1998. "Modelling Economic High-Frequency Time Series with STAR-STGARCH Models." 
Stockholm School of Economics Working Paper Series in Economics and Finance No 291.

McMillan, David G. 2003. "Non-linear Predictability of UK Stock Market Returns." Oxford Bulletin of Economics and Statistics 65(5):557-573.

http://dx.doi.org/10.1111/j.1468-0084.2003.00061.x

Omay, Tolga, Bahar Araz-Takay, Ayşegül Eruygur, and İlker Kilic. 2013. "The Effects of Terrorist Activities on Foreign Direct Investment: Nonlinear Evidence from Turkey." Review of Economics 64(2):139-158.

Pötscher. Benedict M. and Ingmar V. Prucha. 1997. Dynamic Nonlinear Econometric Models: Asymptotic Theory. Berlin: Springer-Verlag.
Teräsvirta, Timo and Heather M. Anderson. 1992. "Characterizing Nonlinearities in Business Cycles Using Smooth Transition Autoregressive Models." Journal of Applied Econometrics 7(S1):119-36.

http://dx.doi.org/10.1002/jae.3950070509

Van Dijk, Dirk Jacobus Cornelis. 1999. "Smooth Transition Models: Extensions and Outlier Robust Inference." Tinbergen Institute Research Series No: 200.

White, Halbert and Ian Domowitz. 1984. "Nonlinear Regression with Dependent Observations." Econometrica 52(1):143-162. http://dx.doi.org/10.2307/1911465

Received on 16-06-2014

Accepted on 01-07-2014

Published on 11-07-2014

DOI: http://dx.doi.org/10.6000/1929-7092.2014.03.17

(C) 2014 Eruygur and Omay; Licensee Lifescience Global.

This is an open access article licensed under the terms of the Creative Commons Attribution Non-Commercial License (http://creativecommons.org/licenses/by-nc/3.0/) which permits unrestricted, non-commercial use, distribution and reproduction in any medium, provided the work is properly cited. 